\title{
Economically Challenged Women in Disaster Risk Management: Toward a Resilient Filipino Community
}

\author{
Teodora Luz S. Mangahas ${ }^{1}$, Rosemarie R. Casimiro², Arneil G. Gabriel ${ }^{3 *}$ \\ ${ }^{1}$ Department of Environmental Science, College of Arts and Sciences, Nueva Ecija University of Science and Technology, \\ Cabanatuan, Philippines \\ ${ }^{2}$ City Disaster Risk Reduction and Management Office, Local Government of Cabanatuan, Cabanatuan, Philippines \\ ${ }^{3}$ Department of Public Administration, Nueva Ecija University of Science and Technology, Cabanatuan, Philippines \\ Email: *gabrielarneil77@gmail.com
}

How to cite this paper: Mangahas, T.L.S., Casimiro, R.R. and Gabriel, A.G. (2018) Economically Challenged Women in Disaster Risk Management: Toward a Resilient Filipino Community. Open Journal of Ecology, 8, 42-56.

https://doi.org/10.4236/oje.2018.81004

Received: December 15, 2017

Accepted: January 26, 2018

Published: January 29, 2018

Copyright $\odot 2018$ by authors and Scientific Research Publishing Inc. This work is licensed under the Creative Commons Attribution International License (CC BY 4.0).

http://creativecommons.org/licenses/by/4.0/

\begin{abstract}
The social and cultural norms shape gender roles which sometimes deprive women of the opportunity to prepare for natural calamities. But the disastrous effect of natural disasters spares no one. It knows no gender. Most of the time, women more than men bear the worse of consequences. The study measures and describes the impact of disaster preparedness sessions on the perception of economically challenged women in Philippines. By using a mixed qualitative and quantitative research method the study found that: 1) the majority of women participants are willing to undergo training in disaster preparedness; 2) their awareness in disaster preparedness improved from "basic" to "high" level; 3) their level of action in disaster preparedness is still on the "planning stage" and; 4) the program effectively changed their attitude towards disaster preparedness and mitigation. The study provided insights on the potential of women in disaster preparedness toward a disaster resilient Filipino community.
\end{abstract}

\section{Keywords}

Sustainable Development, Gender Awareness, Natural Calamities, Economically Deprived Women, Disaster Awareness

\section{Introduction}

The social and cultural norms shape gender roles. The acceptable and desirable behavior in many societies is thus far, typically dictated by the concept of femininity or masculinity, gender stereotypes, and cultural norms. Customarily, men 
are deemed superior to women and are given more access to opportunities. Such perception regarding gender roles on the other hand pushes women to strive harder to have equal privileges and to have a decent life. Despite many accomplishments in empowering women, issues which are negatively affecting their well-being remain unrecognized. These problems include among others, limited access to resources, poverty, and higher vulnerability to environmental hazards and disaster impact. Although disasters affect everyone, regardless of age, gender, and status, women, particularly those in the developing countries have been affected by natural catastrophes differently than men [1]. They are also paid less compared to male counterparts. Many women who belong to the marginalized sector are deprived of access to quality education and social justice [2]. In many societies, gender roles define one's rights including how men and women should think, behave, and interact.

\subsection{Human Ecology and the Interplay of Social Community and Environmental Disaster}

Human beings and the environment have a clear connection. Humans depend on nature for air, water, food, and shelter. Nature, on the other hand, needs humans to cultivate the soil and protect the habitat of animals. However, because of human's pursuit for higher income and material security, the symbiotic relationship between the community and environment is abused. The prevailing anthropogenic perception on the significance of natural resources disrupts the symbiotic relation. Needless to state, the current ecological situation and extreme weather conditions are the results of man's abuses of the environment. Every year, during the last decade, naturally-occurring phenomena such as heavy rainfall, storms, flooding, landslides, and drought affect more than 200 million people in the Asia-Pacific Region alone [3]. Women, who are entirely dependent on farm produce, have to endure the effects of unpredictable weather-related events such as drought and intermittent rainfall [4]. The situation calls for mitigation, preparedness, and capacity-building measures important to help farmers emerge from poverty.

The Philippines, an island country with vast agricultural lands, is globally known as one of the world's most vulnerable countries when it comes to natural hazards. In fact, based on the 2016 World Risk Index, Philippines is the third most at risk to calamities worldwide as it is geographically located along the Typhoon Belt and the Pacific Ring of Fire [5]. Almost 60 percent of the country's total land area is exposed to natural hazards whereas about 74 percent of the population has a high vulnerability to disasters. The country experiences about 20 typhoons or tropical cyclones every year and six to eight of which, affect the mainland; injures people, and destroys hard-earned possessions. Thousands of lives, on the average are lost annually due to disasters. Tropical cyclones and associated flooding constitute about 75 percent of recorded deaths and 63 percent of actual damages [6]. 
The frequency and intensity of these calamities require an effective and efficient response from the national down to the local government units. Climate change heightens disaster risk yet the extent of damages to life and properties vary depending on how well the government and the community have prepared for the emergence of any catastrophe [7]. The impact of the disaster is often exacerbated by high exposure to a hazard, conditions of vulnerability, and insufficient capacity of the community to act or cope with the effects of prevailing risks [8]. Data from the National Anti-Poverty Commission and National Statistical Coordination Board indicates that if confronted by health problems, the death of a family member, loss of job, and disasters, forty-five percent of the Philippine population might fall into poverty [9]. Because of this, the Philippine Government has been doubling its efforts to reduce poverty among its people and to mitigate the effects of both natural and human-induced hazards. Poverty alleviation and disaster management strategies, therefore, have been introduced and mainstreamed into various laws and programs.

\subsection{Women's Experiences in Natural Hazards}

More than a hundred million women have to endure the impacts of disasters every year because of gender inequalities, socio-economic conditions, cultural traditions, and limited access to information and early warnings [10]. According to the United Nations Office for Disaster Risk Reduction (UNISDR), women worldwide are more exposed to disaster risks than men and also have higher rates of mortality and morbidity [11]. Based on records, women accounted for 90 percent of the 140,000 fatalities in the 1991 flooding in Bangladesh; 55 to 70 percent of deaths following the Banda Aceh, Indonesia tsunami in 2004; and 61 percent of the deaths due to Cyclone Nargis in Myanmar in 2008 [12]. In most cases, the inability of women to immediately escape from emergency situations like hydro meteorological catastrophes is associated with their physical limitations such as difficulty climbing trees and inability to swim; as well as, their incapacity to exercise freedom of choice. The problem continues in refugee camps as women and girls are exposed to higher risks because of conflict over scarce resources. Such situations threaten survival and aggravate stress levels in the family and at times lead to increased incidence of domestic violence [13]. The delivery of prenatal care also decreases after a disaster resulting to high-risk pregnancies and poor maternal and fetal outcomes [14]. The disaster situation makes women suffer from both physical and emotional burden [10]. Significantly, to address the plight of millions of women in different parts of the world, gender issues have been mainstreamed into the Millennium Development Goals, laws, and policies. Indeed, promoting gender equality and empowering women are fundamental to human progress and sustainable development [15]. In the Philippines, the devastation caused by Typhoon Ondoy (Ketsana) in 2009 showed the helplessness of humans against natural calamity. The magnitude of damage to persons and properties convinced the lawmakers of the need to ratify 
Republic Act 10,121 otherwise known as the Philippine Disaster Risk Reduction and Management Act of 2010. The primary goal is to strengthen the Philippine Disaster Management system and develop policies and plans to address all aspects of disaster risk reduction and management. In fact, Section 2(a) of the Act states that it shall be the policy of the State to uphold the people's constitutional rights to life and property. For this purpose, key strategies have been developed namely; evaluate the causes of vulnerabilities to disasters; strengthen community institutions to cope with the hazards posed by disasters, and build a climate change resilient communities [16].

\subsection{Preparing Economically Challenged Women for Their Role in Community Disaster Risk Reduction and Management}

Disasters may aggravate social inequalities. Yet, women's increased vulnerability and exposure to hazards and risks based on social practice is a painful reality. Gender roles should be maximized and used as an advantage rather than an excuse to limit women's potential contributions in all phases of the disaster management cycle. Educating women on their capacity to prepare for, and respond to disasters can influence their behavior [17]. By gaining new knowledge and skills, and by incorporating what was learned to further the family's emergency preparedness, community resilience will be more attainable. In Cabanatuan, when there are calamities, men are engaged in the dissemination of early warning, preemptive evacuation and rescue operations. While women, on the other hand, are left in their homes as they took charge in the safekeeping of belongings, emergency supplies, and in ensuring the welfare of children, elderly, and person with disabilities. But their task does not end there because in spite all these, women can take care of themselves and other people in the wake of disasters [10]. Women's participation is crucial in managing disaster risks. Thus, adequate capacity building measures should be done to empower women and to harness their abilities.

Meanwhile, the Department of the Interior and Local Government (DILG) as the Vice Chair for Disaster Preparedness, and the Department of Social Welfare and Development (DSWD) as Vice Chair for Disaster Response, converge through Joint Memorandum Circular 2016-01 to implement the LISTONG Pamilyang Pilipino Program, a program component of DILG's Operation LISTO intended to provide Family Development Sessions (FDS) to the beneficiaries of Pantawid Pamilyang Pilipino Program (4Ps) or what is commonly-known as the Conditional Cash Transfer (CCT) Program [18]. The Conditional Cash Transfer (CCT) Program of the Philippine government has been modeled after the CCT program of Latin America, Caribbean, Mexico, and Brazil. It is a short-term poverty reduction and social development strategy for the provision of conditional cash grants to extremely poor households. To obtain the poorest families in cities and municipalities, the Department of Social Welfare and Development uses an assessment tool known as the National Household Targeting System for 
Poverty Reduction (NHTS-PR). To continue receiving social support from the program, they are required to attend Family Development Sessions (FDS). The sessions target is to enhance the skills and understanding of the grantees regarding family values, marital relationships, parental responsibilities, financial and home management, and active involvement in community development endeavors. Topics such as livelihood opportunities, gender equality, disaster risk reduction and management, and environmental protection are components of the lectures.

This paper discusses the perception of economically challenged women towards risk reduction and management system integrated in the Family Development Sessions for CTC Program beneficiaries. It determines their willingness to participate and change behavior brought about by the program lecture and discussions. It also discusses the implication of the study and the potential of women to contribute to the overall effort of the government on risk reduction and management.

\subsection{Objectives of the Study}

The study endeavors to determine the perception of selected economically challenged women on disaster preparedness training as part of Family Development Sessions in Cabanatuan City Philippines.

Specifically, the study aims to:

1) Describe the perception of the beneficiaries towards the inclusion of disaster risk reduction and management to the Family Development Sessions.

2) Describe the willingness of the beneficiaries to join the Family Development Sessions through:

2.1) Attendance to family development sessions

2.2) Eagerness to participate in activities, workshops, and mock drills

2.3) Compliance with requirements of the program.

3) Determine whether participation in Family Development Sessions brought change in the knowledge, behavior, and practices of the beneficiaries as manifested in their household emergency/disaster preparedness.

4) Determine the implication of the findings on the women's role in community disaster preparedness.

\section{Methodology}

\subsection{Study Locale}

The study area is in Cabanatuan $\left(15.4865^{\circ} \mathrm{N}, 120.9734^{\circ} \mathrm{E}\right)$, a first class city in the province of Nueva Ecija, Philippines. Its geographical condition exposes it to natural hazards. The city has 39 high-risks, 17 medium-risks, and 33 low-risks barangays and is recognized as one of the flood-prone areas in Region III [19]. The recent data showed that in 2015, it has a total population of 302,231 [20]. Of which, around 150,000 people from high-risk barangays are submerged in chestdeep to roof-high flood water. Whereas, 67,000 people from medium-risk, and 
82,000 people from low-risk barangays sometimes suffer from flooding ranging from 0.9 meters (waist-deep) to 0.5 meters (knee-deep). The occurrence of typhoons resulting to extensive flooding has, from time to time, disrupts the economic activities of the city and leads to the displacement of many families. With the city's fast economic development, the rate of population growth, and the ill-effects of climate change, both natural and human-induced hazards is expected to intensify in years' time.

\subsection{Sampling Technique}

The City of Cabanatuan, in the province of Nueva Ecija, Philippines has been chosen as the venue for the study. The city is prone to calamities as it serves as a catch basin when there are typhoons and widespread flooding. In fact, among the 89 barangays, 39 are considered high-risk, 17 are considered medium-risk, and 33 are considered low-risk. For the study, three barangays were selected based on their level of flood susceptibility and the beneficiaries' compliance rate on the Family Development Sessions and Disaster Preparedness and Risk Reduction training and seminars. These are Barrera for High-Risk, Sangitan East for Medium-Risk and Mabini Extension for Low-Risk barangay. Data gathering was conducted in the City of Cabanatuan from August to October 2017. From each barangay, the researcher picked 30 women respondents who are part of the Conditional Cash Transfer (CCT) Program and attends trainings on disaster preparedness to participate in the survey and interview and to represent the other beneficiaries of the sample barangays. Table 1 shows the scoring used in the analysis and interpretation of data collected from the survey.

\subsection{Theoretical Framework}

To describe the selected economically challenged women's perception of the integration of disaster risk reduction and management module in the Family Development Sessions the study adopted the Social Cognitive Theory (SCT). This theory was developed by Albert Bandura and asserts that human behavior changes through a three-way, interrelated model linking personal factors, environmental influences, and behavior (see Figure 1). A basic premise of the Social Cognitive Theory is that people learn through experience, by adopting other's behavior and practices [21].

The study also adopted a similar principle known as Social Ecological Model.

Table 1. Scoring guide used to interpret survey responses.

\begin{tabular}{ccccc}
\hline Weighted Mean & \multicolumn{3}{c}{ Verbal Interpretation } \\
\hline $1-1.5$ & Never & Basic & Not applicable & Ineffective \\
$1.6-2.5$ & Seldom & Average & Do not want to do & Least Effective \\
$2.6-3.5$ & Sometimes & High & Planning to do & Effective \\
$3.6-4.5$ & Always & Very High & Have done & Most Effective \\
\hline
\end{tabular}


The model (Figure 2) helps recognize different factors that influence behavior such as individual, interpersonal, organizational, community and public policy.

\subsection{Paradigm of the Study}

The diagram (Figure 3) conceptualized by the author based on the theories and models presented and on the data collected illustrates the idea that women's perception of disaster and desire to prepare for emergency situations/actions are influenced by factors such as previous experience, perceived needs, and knowledge

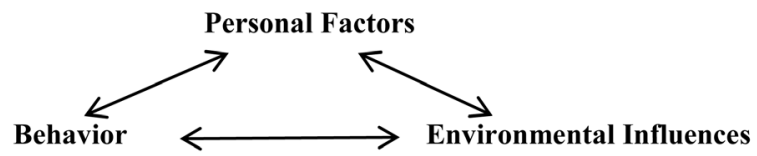

Figure 1. Social cognitive theory (adopted from Bandura, A., (1986): Social foundations of thought and action: A social cognitive theory, prince hall, p. 24).

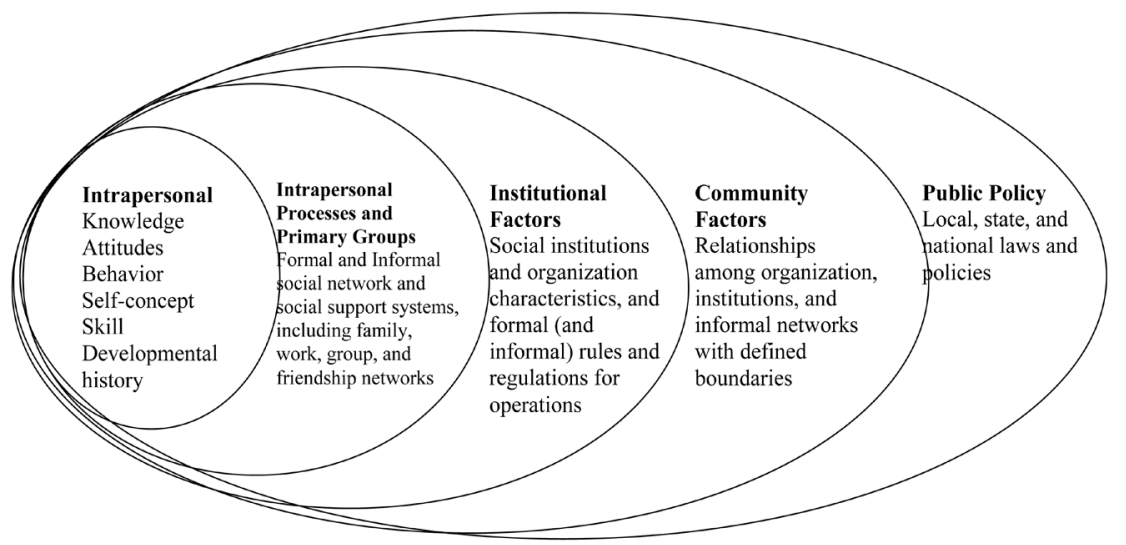

Figure 2. The social ecological model.

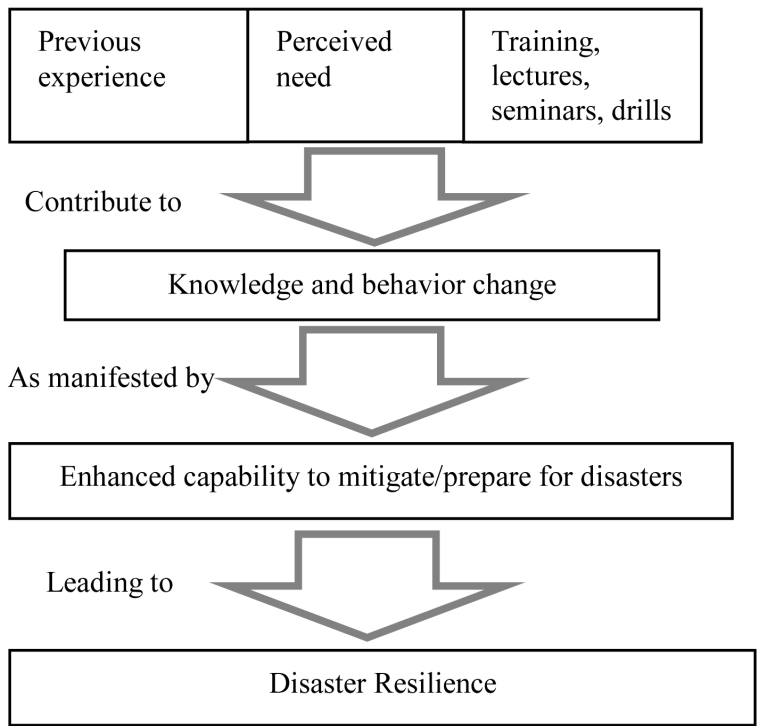

Figure 3. Conceptual framework for women in disaster preparedness: toward a Disaster Resilient Filipino Community. 
of hazards and disasters. Developing a deeper understanding of risks and vulnerabilities also contributes to their decision to change their behavior and attitude towards disaster management. The positive behavior and outlook also persuade women to apply what was learned from the training, lectures, seminars, and drills to protect their family and assets from possible destruction. As a result of continuous practice, women and their family develop resilience against known threats.

\section{Results and Discussion}

\subsection{Socio-Demographic Data of Respondents}

The respondents of the study were 90 women beneficiaries of Conditional Cash Transfer Program of the Government from three barangays (high-risk, mediumrisk, and low-risk) of Cabanatuan City. Most of them are within 31 to 40 years old and within child bearing or maternal age. They receive grants for their school-age children upon meeting the conditions of the program. On the other hand, as evident in many studies, this age group also bears more of the responsibility of caring for children, elderly, the sick, and injured in times of emergency. Such setting adds up to the burden of women and may affect their early recovery post-disaster. Fortunately, in the study area, to respond to the needs of women in evacuation centers has become a protocol. This is to ensure the safety of women and designate breastfeeding areas for lactating mothers. Majority of the participants or 40 percent, are High School Graduates and Elementary Graduates $(30 \%)$. Studies in the area of disaster preparedness and education found positive correlations between the two. Several studies suggest that the impact of calamities vary from one individual to individual because of differences in knowledge and perception on the dangers of potential hazards, preparedness, interpretation of warnings received, and access to electronic media [22].

Most of them have jobs during the time of data gathering. Some of them are self-employed or engaged in small businesses such as selling goods in the market while some are engaged in farming. Several studies relate occupation or income with disaster preparedness. The high-income population is seen to be more prepared and less vulnerable before, during, and even after natural disasters than low-income population [14]. Other studies also stated that if people have a source of income, they will have more resources such as television, radio, and vehicle, which they can use to monitor the situation and help them in the evacuation.

Based on the gathered data, most of the respondents belong to a household with six or more members (53\%) in which women's population outnumbers men. It shows that when flooding occurs, their family members are among the priorities for evacuation.

All respondents agree that they have experienced calamities in the past. Moreover, among the natural catastrophes, typhoon and flooding are the most frequent. Flooding, as described by the respondents from both high-risk and medium-risk barangays are felt almost every year. Meanwhile, respondents from 
the low-risk barangay said that despite the frequent occurrence of typhoons, they seldom suffer from flooding because the location of their barangay is slightly elevated. On the other hand, all respondents demonstrate an understanding of the susceptibility of their barangay to flooding. However, for them to classify whether their barangay is high-risk, medium-risk, or low-risk, the depth or level of flood-water has to be described. Studies show that an individual's perception of the existence and magnitude of risk affect his or her preparations and decision-making. People who have experienced calamitous events are more serious in their preparations and are more likely to attend seminars and training to have a deeper understanding of the phenomenon [23].

\subsection{Willingness to Participate in Family Development Sessions}

Beneficiaries of Conditional Cash Transfer Program are required to attend Family Development Sessions for a good cause. The Table 2 illustrates how many of the respondents attend, participate and comply with the requirements of the Family Development Sessions which is a component of the program.

As shown in Table 2, all respondents from the three barangays said that they "Always" attend Family Development Sessions, lectures, and seminars. Majority of respondents with the mean score of 3.73 said that they eagerly participate in workshops and drill exercises. Although it has a verbal interpretation of "Always", some says that occasionally, they do not eagerly participate in workshops and drill exercises because they do not recognize the need to do so since they are seldom affected by flooding. Almost all of the respondents said that they submit the requirements on time. Nevertheless, according to some, they do comply because it is part of the conditions for the cash assistance and for them to stay in the program.

Their responses reflect the need for further orientation on the purpose of doing workshops and drill exercises. It is important to stress that their participation will eventually prove to be useful especially in the actual situation.

\subsection{Level of Disaster Awareness and Preparedness of the Selected Economically Challenged Women}

Among the objectives of the conduct of Family Development Sessions is to

Table 2. Respondents' willingness to participate in family development sessions.

\begin{tabular}{cccccc}
\hline & \multicolumn{6}{c}{ Barangay } \\
\hline & A & B & C & Mean & Verbal Description \\
\hline Attend Family Development Sessions & 4 & 4 & 4 & 4 & Always \\
$\quad \begin{array}{c}\text { Attend lectures and seminars } \\
\begin{array}{c}\text { Eagerly participate in workshops and } \\
\text { drill exercises }\end{array}\end{array}$ & 4 & 4 & 4 & 4 & Always \\
$\begin{array}{c}\text { Comply with the assignments and other } \\
\text { requirements of the program }\end{array}$ & 3.9 & 3.7 & 4 & 3.73 & Always \\
$\quad$ Overall Mean & 3.85 & 3.90 & 3.975 & 3.90 & Always \\
\hline
\end{tabular}

Legend: 1 - 1.5 never; 1.6 - 2.5 seldom; 2.6 - 3.5 sometimes; 3.6 - 4.5 always. 
increase the level of awareness of the community to the threats and impacts of all hazards. Table 3 shows the level of awareness and preparedness of the beneficiaries before and after the training.

Table 3 shows the respondents' level of awareness of hazards within the community and their preparedness before and after the training. Based on the data, the level of awareness of all respondents improved from Basic to High. Therefore, the program has been effective in enhancing the knowledge of grantees regarding disaster risks. Having developed their awareness of disaster management, they are more capable of initiating change from household and eventually to the community level.

Although their level of preparedness has improved by merely one step, from Basic to Average, still, it is something to be proud of. Besides, they have plans of incorporating what they have learned to further the level of preparedness of their family. The low rating is attributed to their perception that individual preparedness is not enough as it should be shared by all members of the family and should be tested on the actual scenario.

Also, all of them said that after the training, they would upgrade their family's disaster preparedness approach. As the member of the household, and as mothers who only want the best for the family, they want their kin to adopt the right precautionary and disaster preparedness measures.

Because of what they have learned and experienced from the Family Development Sessions, they are willing to participate in similar training if given the opportunity. Nevertheless, to avoid repetition, there should be different approach such as sharing of best practices.

It has been a part of the Conditional Cash Transfer Program to involve beneficiaries in clean-up drives and tree-planting activities. Such endeavor is like a win-win situation wherein grantees are tapped as volunteers for greening programs in exchange for cash incentives. It is like trying to sustain ecological integrity while helping women in their financial struggle and in the realization of their role in the community as the agent of change.

Some of the respondents, however, have different views on whether they will

Table 3. Level of awareness and preparedness.

\begin{tabular}{llccccc}
\hline \multicolumn{7}{c}{ Barangay } \\
\hline & A & B & C & Mean & $\begin{array}{c}\text { Verbal Interpreta- } \\
\text { tion }\end{array}$ \\
\hline BEFORE the training & 1.2 & 1.2 & 1 & 1.13 & Basic \\
AFTER the training & 2.6 & 2.3 & 3 & 2.63 & High \\
BEFORE the training & Level of Preparedness & & Basic \\
AFTER the training & 1.2 & 1.1 & 1 & 1.1 & Average \\
\hline
\end{tabular}

Legend: 1 - 1.5 basic; 1.6 - 2.5 average, 2.6 - 3.5 high; 3.6 - 4.5 very high. 
use the information to encourage their relatives and other residents to participate in DRRM activities. Although they are willing to impart the knowledge they have gained from the training, they want others to acquire the information from resource speakers who have the deeper understanding of the subject matter and can accommodate their queries.

\subsection{Behavior Change as Reflected by the Selected Economically Challenged Women's Household Emergency/Disaster Preparedness}

Positive behavior change is considered a factor in enhancing one's disaster preparedness. Table 4 shows the household emergency/disaster preparedness of the respondents. The level of their preparation is a good indicator of the effectiveness of the program in enhancing their knowledge, perception, and attitude towards disaster-readiness.

The data presented in Table 4 show that despite having plans to perform preparedness measures, most of the respondents remain on the "planning stage" or have not tested the effectiveness of their ideas.

Disaster may occur at any time. Thus, every family should develop a preparedness plan. It includes the role of every member in the safekeeping of belongings and in ensuring that everyone will be safe during the incident. Everyone should be briefed on exit routes and meeting place in case he or she will be separated from one another.

The Cabanatuan City Disaster Risk Reduction and Management Office distribute stickers with hotline numbers. The purpose of which, is for everyone to

Table 4. Household emergency/disaster preparedness.

\begin{tabular}{|c|c|c|c|c|c|}
\hline & \multicolumn{5}{|c|}{ Barangay } \\
\hline & A & $\mathrm{B}$ & $\mathrm{C}$ & Mean & $\begin{array}{c}\text { Verbal } \\
\text { Interpretation }\end{array}$ \\
\hline $\begin{array}{l}\text { Discussed with family members what to do in case of a } \\
\text { natural calamity or emergency }\end{array}$ & 2.8 & 3.6 & 3.6 & 3.33 & Planning to do \\
\hline Developed a Family Disaster Preparedness Plan & 3.3 & 3.6 & 3.5 & 3.46 & Planning to do \\
\hline $\begin{array}{l}\text { Performed emergency simulation/reenactment in the } \\
\text { household from time to time to test the effectiveness of } \\
\text { the family preparedness plan }\end{array}$ & 3.1 & 3.1 & 3 & 3.06 & Planning to do \\
\hline $\begin{array}{l}\text { Kept a record of the emergency hotline numbers } \\
\text { (rescuer, hospitals, barangay officials, fire stations, etc.) } \\
\text { that can be contacted in case of emergency }\end{array}$ & 3.6 & 3.7 & 3.6 & 3.63 & Have Done \\
\hline Prepare an Emergency Go Kit/E-balde & 4 & 3.7 & 3.9 & 3.86 & Have Done \\
\hline $\begin{array}{l}\text { Helped a relative or neighbor prepare an } \\
\text { Emergency Go Kit/E-balde }\end{array}$ & 3.5 & 3.1 & 3.2 & 3.26 & Planning to Do \\
\hline Overall Mean & 3.38 & 3.46 & 3.46 & 3.43 & $\begin{array}{l}\text { Planning } \\
\text { to Do }\end{array}$ \\
\hline
\end{tabular}

Legend: 1.0 Legend: 1 - 1.5 not applicable; 1.6 - 2.5 do not want to do; 2.6 - 3.5 planning to do; 3.6 - 4.5 have done. 
have a copy of the telephone and mobile numbers which he or she can call in times of emergencies. Most of the respondents believe that keeping the contact numbers of emergency frontline agencies will be an advantage in times of need. However, because of financial constraints, some do not own a cellular phone which is needed to call the mentioned agencies. Nonetheless, they keep the contact numbers for future reference.

The preparation of an E-balde or emergency pail is part of the disaster preparedness training. The balde or pail/bucket which is a common item in the household has been given another purpose. Aside from its typical use as storage for water, the beneficiaries are taught to use pail as storage for clothes, important documents, canned goods, medicines, and other personal belongings. The ebalde is ideal in emergency situations and for women because it is handy, waterresistant, and easily-available. The E-balde is a reflection of the Filipino's creativity and adaptability. And likewise, support the idea that women can prepare for disasters using materials commonly found at home. It is good to know that there are households in the locale that maintains an E-balde yet; considering the result of the survey; there is a need to ease the reluctance of few respondents to help others to prepare an E-balde. Women, who are naturally sociable, should be tapped to create a culture of disaster preparedness in the neighborhood.

\subsection{Perceived Effects of Disaster Risk Reduction and Management Training to Economically Challenged Women}

Table 5 presents the effect of disaster risks reduction and management training

Table 5. Perceived effects of disaster risk reduction and management training to economically challenged women.

\begin{tabular}{|c|c|c|c|c|c|}
\hline \multirow[b]{2}{*}{ Reasons } & \multicolumn{5}{|c|}{ Barangay } \\
\hline & A & B & $\mathrm{C}$ & Mean & $\begin{array}{c}\text { Verbal } \\
\text { Interpretation }\end{array}$ \\
\hline $\begin{array}{l}\text { Attendance to Family Development Sessions } \\
\text { has changed my perception towards the } \\
\text { importance of disaster preparedness. }\end{array}$ & 3.4 & 3.4 & 3.7 & 3.5 & Effective \\
\hline The inclusion of disaster training to Family & & & & & \\
\hline $\begin{array}{l}\text { Development Sessions made me to be more } \\
\text { disaster-aware and disaster ready. }\end{array}$ & 3.7 & 3.6 & 3.7 & 3.66 & Most Effective \\
\hline $\begin{array}{l}\text { The topics included in the module are } \\
\text { interesting and time-worthy. }\end{array}$ & 2.9 & 3 & 3.2 & 3.03 & Effective \\
\hline $\begin{array}{l}\text { The topics made me more willing to develop } \\
\text { the family's disaster preparedness plan. }\end{array}$ & 3.2 & 3.1 & 3.2 & 3.16 & Effective \\
\hline $\begin{array}{c}\text { The inclusion of community risk assessment } \\
\text { to the Family Development Session has } \\
\text { transformed the attitude of participants } \\
\text { towards their role in mitigating and } \\
\text { preparing for disasters }\end{array}$ & 3.2 & 3.2 & 3.3 & 3.23 & Effective \\
\hline Overall Mean & 3.28 & 3.26 & 3.42 & 3.31 & Effective \\
\hline
\end{tabular}

Legend: 1.0 - 1.5 ineffective; 1.6 - 2.5 least effective; 2.6 - 3.5 effective; 3.6 - 4.5 most effective. 
to the sample population composed of economically challenged women in the City of Cabanatuan.

All the respondents from the three barangays said that their attendance to Family Development Sessions has brought about change in their perception towards the importance of disaster preparedness. Therefore, the program has been "effective" in encouraging the respondents to change their perception towards the importance of disaster preparedness. Likewise, they also said that the inclusion of disaster training to Family Development Sessions has been "most effective" in making them more disaster-aware and disaster-ready. The result of the survey indicates that the inclusion of Family Development Session has been a valuable means for the dissemination of disaster knowledge to include the economically-challenged women in the community.

The respondents perceive the topics included in the module as thought-provoking and time-worthy. Discussions are also interactive and urge them to voice their point of views and experiences. The mothers who participated in the sessions also learn to share the information with their family members, especially to their children.

Lastly, the majority of the respondents agree that the inclusion of community risk assessment to the Family Development Session has transformed their attitude towards their role in mitigating and preparing for disasters. After gaining more knowledge on community risks and preparedness measures, their notion that women are generally "helpless" changed into the impression that women are "helpers" and that they can contribute to the early recovery of the community.

\section{Conclusions and Recommendations}

\subsection{Conclusions}

Given the location of Philippines, the occurrence of natural calamities is inevitable. Moreover, the phenomenon is exacerbated by the effects of climate change which is becoming a global concern. Women, because of their limited access to resources, were more vulnerable to disasters.

Philippines, which is among the countries who advocate for gender equality and inclusive development, has been implementing various policies and laws to ensure the protection of women, especially in crisis situations.

Republic Act 10121 or the Philippine Disaster Risk Reduction and Management Act of 2010 not only promotes gender equality but also espouses the "whole of society" and proactive approach to disaster management. For this cause, training on disaster risk reduction and management was incorporated to the Family Development Sessions (FDS) for the beneficiaries of Pantawid Pamilyang Pilipino Program (4Ps), the Philippines' version of Conditional Cash Transfer (CCT) Program of Latin America and the Caribbean.

Dissemination of information on disaster is just one of the elements in building disaster-resilient Filipino communities. Nevertheless, its positive effect on 
the behavior and perception of women towards disaster preparedness will prove to be beneficial in the long run. As evident in the study, the Family Development Sessions have been a good modality for harnessing the knowledge and skills of women on disaster management. Women, who are often left at home to look after the children, have learned to use the information to make their family disaster-ready.

The study, therefore, reinforces the idea that gender-inclusive programs are vital to the achievement of community resilience.

\subsection{Recommendations}

Educating women about disaster risks and management provides opportunities to decrease women's vulnerability. In the long run, having developed women's adaptive capability, or the ability to withstand the effects of disasters or immediately recover from disasters and external shocks, will be essential in building resilience from grassroots to the national level.

Women play a crucial role in the disaster risk reduction and management process. Women should be empowered, and their role as drivers of change and helpers in the wake of disasters should be encouraged. Because they understand the consequences disasters have on their community as well as, their potential long-term impacts, women can also be proactive. Women's naturally caring and nurturing nature drives them to make a difference for the future of their children and of the community as a whole. Women also have the eye for details, and this makes them a pivotal part of the planning process.

Further evaluation of the program in some barangays is encouraged to look for similarity in results and check the usefulness of RA 10121 in disaster preaparedness and reduction. A more in-depth study should be made to include all barangays of Cabanatuan City to elicit the point of views of all program beneficiaries. Future researchers should also look into the other factors that will further improve the program and its outcomes.

Information dissemination and women empowerment should be given due course to strengthen the community preparedness against disasters.

Design and innovate gender inclusive programs intended to reinforce existing structure that provides women the opportunity to contribute to the development of society not only in disaster management and other areas of natural and social activities.

\section{References}

[1] United Nations Population Fund (UNFPA) (2009) State of the World's Population 2009. UNFPA, New York.

[2] Gabriel, A.G. (2017) Indigenous Women and the Law: The Consciousness of Marginalized Women in the Philippines. Asian Journal of Women's Studies, 23, 250-263. https://doi.org/10.1080/12259276.2017.1317705

[3] United Nations Economic and Social Commission for Asia and the Pacific (UNESCAP) (2011) Statistical Yearbook for Asia and the Pacific, Thailand. 
[4] SOFA Team and Cheryl Doss (2011) Role of Women in Agriculture. http://www.fao.org/docrep/013/am307e/am307e00.pdf

[5] Institute for Environment and Human Security (UNU-EHS), United Nations University (2016) World Risk Report 2016.

https://ehs.unu.edu/blog/articles/world-risk-report-2016-the-importance-of-infrastr ucture.html

[6] ADB, National Disaster Coordination Council, and United Nations (2008) National Assessment on the State of Disaster Risk Management in the Philippines. Final Report, Manila.

[7] World Conference on Disaster Reduction (2005) Hyogo Framework for Action: Building the Resilience of Nations and Communities to Disasters.

http://un-documents.net/hfa.htm

[8] UN System Task Team on the Post-2015 UN Development Agenda. http://www.unisdr.org/files/30374_thinkpieceondrmfinal.pdf

[9] Government of the Philippines, National Anti-Poverty Commission and National Statistical Coordination Board (2005) Assessment of Vulnerability to Poverty in the Philippines. Manila.

[10] UNISDR (2012) Women, Girls, and Disasters.

[11] United Nations International Strategy for Disaster Reduction (UNISDR) (2008) Climate Change and Disaster Risk Reduction. Briefing Note 1, September.

[12] Women's Environment and Development Organization (WEDO) (2008) Gender, Climate Change and Human Security. http://www.gdnonline.org/resources/WEDO_Gender_CC_Human_Security.pdf

[13] UNDP (2013) Gender and Climate Change Asia and the Pacific Policy Brief.

[14] Committee on Health Care for Undeserved Women (2010) Preparing for Disasters: Perspectives on Women. American College of Obstetricians and Gynecologists, Washington DC. https://www.ncbi.nlm.nih.gov

[15] World Health Organization. http://www.who.int/topics/millennium_development_goals/about/en/

[16] Republic Act 10121.

[17] http://www.unisdr.org/files/46052_disasterriskreductioninthe2030agend.pdf

[18] Social Protection Note (2012) Design and Implementation Features of the National Household Targeting System in the Philippines by Luisa Fernandez.

http://documents.worldbank.org/curated/en/687351468093838577/pdf/701490BRI0 P118010Protection0Note005.pdf

[19] Based on the Data of Cabanatuan City Disaster Risk Reduction and Management Office.

[20] https://www.psa.gov.ph/content/population-region-iii-central-luzon-based-2015-ce $\underline{\text { nsus-population }}$

[21] Bandura, A. (1971) Social Learning Theory. General Learning Corporation, December 2013.

[22] Mohammad-pajooh, E. and Aziz, K.A. (2014) Investigating Factors for Disaster Preparedness among Residents of Kuala Lumpur.

https://www.nat-hazards-earth-syst-sci-discuss.net/2/3683/2014/nhessd-2-3683-201 4-print.pdf

[23] Digian, S. (2005) Socio-Economic Variables as Indicators of Preparedness Level in Cyclone Events. James Cook University, Townsville, Queensland. 